Research Paper

\title{
Cyclin AI Is Expressed in Mouse Ovary
}

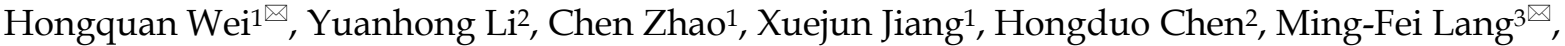 \\ Jing $\operatorname{Sun}^{1,4} \bowtie$ \\ 1. Department of Otolaryngology, The First Hospital of China Medical University, Shenyang, Liaoning 110001, P.R. China; \\ 2. Department of Dermatology, The First Hospital of China Medical University, Shenyang, Liaoning 110001, P.R. China; \\ 3. Department of Physiology, Dalian University Medical School, Dalian, Liaoning 116622, P.R. China; \\ 4. Current address: Department of Medical Laboratory Science and Biotechnology, Dalian University Medical School, Dalian, Liaoning \\ 116622, P.R. China.
}

\begin{abstract}
$\square$ Corresponding authors: Department of Otolaryngology, The First Hospital of China Medical University, 155 North Nanjing Street, Shenyang, Liaoning 110001, P.R. China. Hongquan Wei, MD. PhD. Email: hongquanwei@hotmail.com, Phone: 86-13940437387. Jing Sun, PhD. Email: sunjing010@yahoo.com. Department of Physiology, Dalian University Medical School, Dalian, Liaoning 116622, P.R. China. Ming-Fei Lang, MD, PhD. Email: langmf@hotmail.com.

(C) Ivyspring International Publisher. This is an open-access article distributed under the terms of the Creative Commons License (http://creativecommons.org/ licenses/by-nc-nd/3.0/). Reproduction is permitted for personal, noncommercial use, provided that the article is in whole, unmodified, and properly cited.
\end{abstract}

Received: 2013.II.05; Accepted: 2014.04.0I; Published: 20I4.05.15

\begin{abstract}
Cyclin AI belongs to the type-A cyclins and participates in cell cycle regulation. Since its discovery, cyclin AI has been shown mostly in testis. It plays important roles in spermatogenesis. However, there were also reports on ovary expression of cyclin AI. Therefore, we intended to revisit the expression of cyclin AI in mouse ovary. Our study showed that cyclin AI was expressed at the mRNA level and the protein level in mouse ovary. Tissue staining revealed that cyclin Al was expressed in maturating oocytes. With the recent data on the functions of cyclins in somatic and stem cells, we also discussed the possibilities of further studies of cyclin Al in mouse oocytes and perhaps in the oogonial stem cells. Our findings not only add to the supportive evidence of cyclin $\mathrm{Al}$ expression in oocytes, but also may promote more interest in exploring cyclin $\mathrm{Al}$ functions in ovary.
\end{abstract}

Key words: cyclin A1, ovary, oocyte, expression, testis.

\section{Introduction}

Cell cycles are regulated by various cyclins and their associated kinases. Type-A cyclins (Cyclin A) are involved in DNA replication, centrosome duplication, and mitosis $[1,2]$. There are two types of cyclin A: cyclin A1 and A2. Cyclin A2 is ubiquitously expressed in somatic and germ cells [3]. Mice lacking cyclin A2 is embryonic lethal [4]. However, cyclin A1 expression is mostly restricted to testis $[5,6]$. Mice lacking cyclin A1 are male infertile [7].

Cyclin A1 is encoded by Ccna1. The expression of the Ccna1 is mainly regulated at transcriptional level. Two upstream regions $(-4.8 \mathrm{~kb} /-1.3 \mathrm{~kb})$ of the Ccna1 transcription start site (TSS) were found to be responsible to stimulate the testis-specific and high expression of cyclin A1 [8]. Furthermore, Sp1 and GATA binding sites were recently discovered within positions -290/-120 bp upstream of the TSS [9]. These sites are responsible for the repression of the cyclin A1 expression. Since cyclin A1 is found in late, but not early spermatocytes, the simulative and repressive regulations of the cyclin A1 transcription might explain the unique testis-specific expression patterns of cyclin A1 $[5,10]$.

Though most of the studies support the testis-specific expression of cyclin A1 [7, 11, 12], evidence of ovary/oocyte expression of cyclin A1 is also available $[5,13,14]$. There are still controversies over the ovary/oocyte expression of cyclin A1. Particularly, Persson et al showed that in ovary cyclin A1 was not expressed to a significant level that could be detected at either the mRNA level or the protein level [12].

In this study, we showed that at both the mRNA 
level and the protein level cyclin A1 was detected in mouse ovary/oocyte. This study may provide some additional in vivo evidence that cyclin A1 is expressed in mouse ovary/oocyte and is not only restricted to male reproductive system.

\section{Materials and Methods}

\section{Animals}

C57BL/6 mice (12-week old) were purchased from the Experiment Animal Center of China Medical University, and were sacrificed immediately by euthanasia for tissue collections. Experiments and protocols were approved by the ethic committee, University Animal Care and Use Committee (protocol SCXK-2008-0005).

\section{RT-PCR}

RNAs were extracted from the tissues of the mice by RNAiso reagent (Takara) and were reversely transcribed to cDNAs using the AMV Reverse Transcriptase XL in RNA PCR kit (AMV) Version 3.0 (Takara) according to the manufacturer's instructions. PCR were performed with Ex Taq Hot-Start DNA Polymerase in the RNA PCR kit: $94{ }^{\circ} \mathrm{C}, 2 \mathrm{~min} ; 94^{\circ} \mathrm{C}$, $30 \mathrm{sec}, 54{ }^{\circ} \mathrm{C}, 30 \mathrm{sec}, 72{ }^{\circ} \mathrm{C} 1 \mathrm{~min}$ for 35 cycles; $72{ }^{\circ} \mathrm{C}$, $5 \mathrm{~min}$. The primers were: for cyclin A1 forward: 5'-CGCACAGAGACCCTGTACTT-3'; reverse: 5'-TTGGAACGGTCAGATCAAAT-3', PCR product size is about $250 \mathrm{bp}$; for actin forward: 5'-TGTTACCAACTGGGACGACA-3'; reverse 5'-TCTCAGCTGTGGTGGTGAAG-3', PCR product size is about $390 \mathrm{bp}$.

\section{Tissue Sections}

Tissues from the mice were collected and fixed in $4 \%$ paraformaldehyde at $4{ }^{\circ} \mathrm{C}$ overnight; then rinsed for 30 minutes in PBS three times, and sequentially bathed in 10\%, 20\%, and 30\% sucrose in PBS to cryoprotect until the tissues sank to the bottom. The tissues were embedded with OCT and subsequently

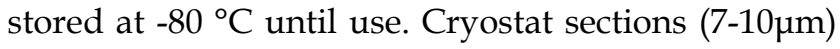
were cut and plated on gelatin-coated glass slides and dried overnight prior to immunofluorescence.

\section{Immunofluorescence}

Immunofluorescence was done as described previously [9]. Briefly, sections were blocked in PBS containing 5\% donkey serum and $0.1 \%$ Triton X-100 then incubated with the following primary antibody: rabbit anti-Cyclin A1 antibody (H-230) (Santa Cruz; 1:200 dilution). The secondary antibodies used were goat anti-rabbit Alexa 594 (Molecular Probes; 1:800 dilution).

\section{Results}

\section{Expression of Cyclin AI mRNA in Different Tissues}

We first examined expression of cyclin A1 in various mouse tissues by RT-PCR (Fig. 1). Cyclin A1 was expressed in mouse testis, as expected. We were also able to detect cyclin A1 in mouse ovary. As a negative control, mouse greater omentum had no expression of cyclin A1. Please note that only the most relevant results were shown in Fig. 1.

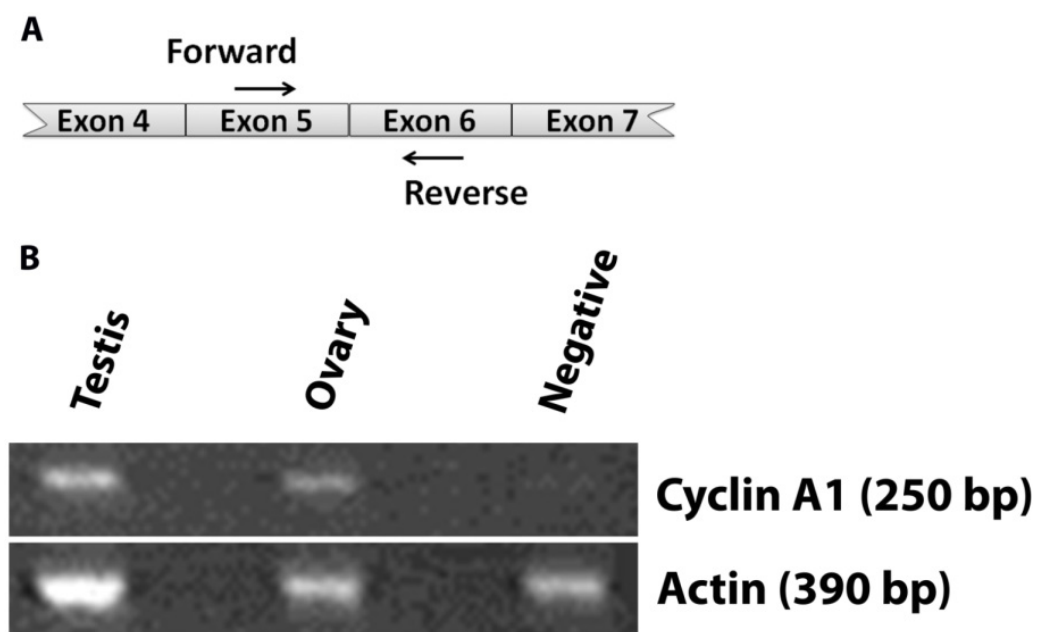

Figure I. Expression of cyclin AI in ovary at the mRNA level A. Illustration showing the cyclin AI cDNA and the locations of the forward and reverse primers. B. The expression of cyclin Al in testis, ovary, and negative control (greater omentum) was detected by RT-PCR. Actin was detected as loading controls. The sizes of the RT-PCR Cyclin AI and Actin products are labeled as $250 \mathrm{bp}$ and $390 \mathrm{bp}$, respectively. 

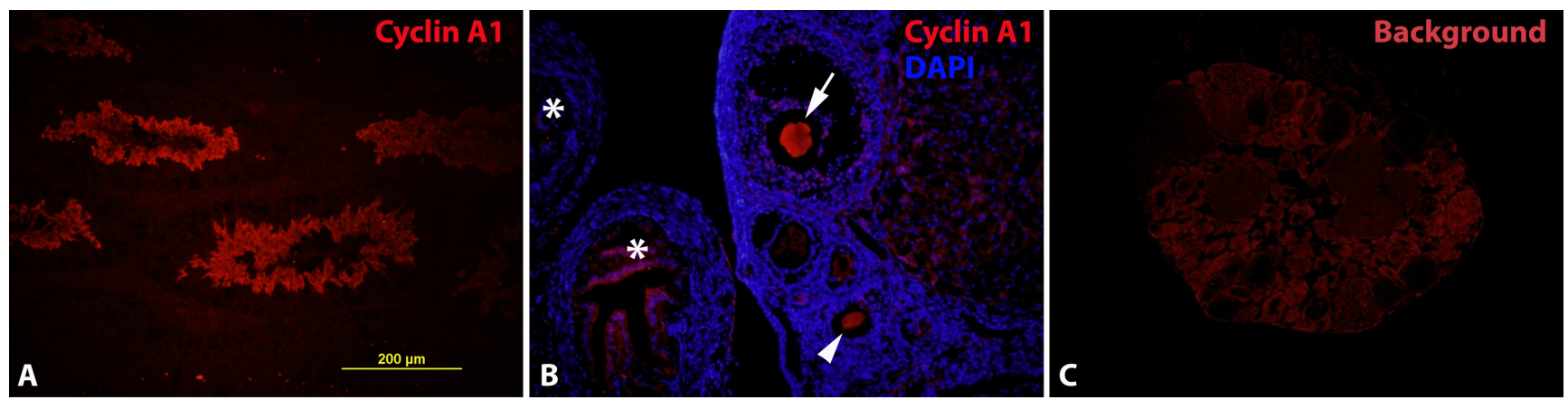

Figure 2. Expression of cyclin Al in maturating oocytes at the protein level A. Cyclin Al expression in testis was examined to confirm the antibody in a cyclin AI positive tissue. B. Cyclin Al expression was detected in oocytes, at various maturating stages. Arrow: oocyte close to ovulation; arrow head: oocyte at an earlier maturating stage; stars: fimbriae of the fallopian tube. C. Background (or non-specific) staining of the ovary without primary cyclin Al antibody.

\section{Validation of the Cyclin AI Antibody}

To further verify the RT-PCR results in ovary, we took immunofluorescence as a more direct approach (regarding the tissue origin) to the cyclin A1 expression in known positive and negative tissues. Our antibodies were able to detect cyclin A1 in mouse testis specifically (Fig. 2A), similar to the results by RT-PCR. However, we didn' $t^{\prime}$ detect cyclin A1 expression in known negative tissues (data not shown). In addition, immunofluorescence without the primary antibody (against cyclin A1) also confirmed the specificity of the staining (data not shown).

\section{Expression of Cyclin AI Protein in Ovary}

After the validation of the cyclin A1 antibody, we set up experiments to detect cyclin A1 expression in mouse ovary. The results (Fig. 2B) showed indeed that cyclin A1 was expressed in ovary. The cyclin A1 expression was not found everywhere in the ovary, but rather in developing/maturating oocytes. By a closer look at the morphologies of the follicles and the oocytes, the oocytes in Fig. 2B were at various maturating stages. The more mature oocyte in Fig. $2 \mathrm{~B}$ was also in close proximity to the fimbriae of the fallopian tube, indicating that the oocyte was near ovulation. The expression of the cyclin A1 was so restricted that most of the other parts of the ovary didn't express it. Fig. 2C was a negative control, showing the background, but non-specific staining in mouse ovary, without the primary cyclin A1 antibody. This negative control was also to indicate the specificity of the antibody.

\section{Discussion}

We intended to revisit the topic of cyclin A1 expression in female reproductive system by assessing at the mRNA and the protein levels. Our findings concluded that cyclin A1 was expressed in oocytes. Though further studies are necessary to uncover the functional roles of such expression, at least the current study adds to the evidence that cyclin A1 is expressed in the female reproductive system. Furthermore, we also showed in vivo and confirmed the cyclin A1 expression in developing oocytes. Presumably, the maturation specific expression patterns may suggest some unique functions in these cell types.

Since the discovery of cyclin A1, there have been different opinions on its sites of expression. Most of the studies support the testis-specific expression [7, $11,12]$. However, ovary expression was also found or implied $[5,13,14]$. In this study, we detected cyclin A1 expression in mouse ovary at the mRNA level and the protein level. Immunofluorescence staining revealed that the cyclin A1 expression was in maturating oocytes, but not in other parts of the ovary. Compared to sperms in testis, oocytes are much fewer in quantities in ovary. This may explain the difficulties in detecting cyclin A1 expression in ovary. Another explanation may be due to the detection methods, sensitivity or specificity, which are more important in detecting low or tempo-spatial gene expressions. It is interesting and significant that cyclin A1 expression was found in maturating oocytes. Cyclin A1 is a cell cycle regulator and forms complexes with cyclin-dependent kinase 1 (CDK1) and CDK2 $[15,16]$. These complexes have been suggested playing roles in DNA double-strand breaks (DSB) repair (required in meiotic recombination) and G2-M transition in meiosis $[7,15,16]$.

Mice lacking cyclin A1 can survive, but males become infertile [7]. These observations indicate that cyclin A1 is not essential for survival but is unique in spermatogenesis. Female mice lacking the cyclin A1 expression was developmentally normal and reproduction was not affected, either. The expression of cyclin A1 in oocytes could also suggest its normal role in oogenesis under wild type conditions. However, it may be more challenging to confirm this, compared to cyclin A1 in spermatogenesis.

It is known that cyclins are redundant [1]. The missing functions of one cyclin can be substituted by 
another, though not completely equivalent. For example, cyclin A1 and A2 ablated fibroblasts cells could proliferate normally but with alterations in cell cycles [17]. These cells were also found to overexpress cyclin $\mathrm{E}$ in a wider cell cycle window. Further deletion of cyclin E shut off cell cycle completely. In this case, cyclin E and cyclin A are redundant in controlling cell cycle progression.

In the same study, it was also shown that cyclin $\mathrm{A}$ and cyclin $\mathrm{E}$ were required by hematopoietic stem cells (HSC) and embryonic stem cells (ESC), respectively [17]. These two cell types are of more stem cell origin than fibroblast. Along this line, it would be interesting to know how cyclin A1 and/or A2 function in the stem cells of oocytes. Recent studies have shown that adult ovary contains stem cells that are capable of replenishing the follicle oocytes [18, 19]. Further studies on how oogonia/oocytes react to alterations of cyclin A will reveal more that were not observed in previous studies. It would be also important to observe the long-term responses (such as follicle pool size), but not only cell cycle changes.

In conclusion, our finding of cyclin A1 expression in maturating oocyte may further support future studies on the role of cyclin $\mathrm{A}$ in female reproductive system.

\section{Acknowledgements}

This study was supported by the National Natural Science Foundation of China (30640003), General Grant (L2010617) of Education Department of Liaoning Province, and Science and Technology Design Program (2011225027) of Science and Technology Agency of Liaoning Province, China.

\section{Competing Interests}

The authors have declared that no competing interest exists.

\section{References}

1. Murray AW. Recycling the cell cycle: cyclins revisited. Cell. 2004; 116: 221-34.

2. Meeran SM, Katiyar SK. Cell cycle control as a basis for cancer chemoprevention through dietary agents. Frontiers in bioscience : a journal and virtual library. 2008; 13: 2191-202

3. Ravnik SE, Wolgemuth DJ. The developmentally restricted pattern of expression in the male germ line of a murine cyclin A, cyclin A2, suggests roles in both mitotic and meiotic cell cycles. Developmental biology. 1996; 173: 69-78. doi:10.1006/dbio.1996.0007.

4. Murphy M, Stinnakre MG, Senamaud-Beaufort C, Winston NJ, Sweeney C, Kubelka M, et al. Delayed early embryonic lethality following disruption of the murine cyclin A2 gene. Nature genetics. 1997; 15: 83-6. doi:10.1038/ng0197-83.

5. Sweeney C, Murphy M, Kubelka M, Ravnik SE, Hawkins CF, Wolgemuth DJ, et al. A distinct cyclin A is expressed in germ cells in the mouse. Development. 1996; 122: 53-64.

6. Wolgemuth DJ, Roberts SS. Regulating mitosis and meiosis in the male germ line: critical functions for cyclins. Philosophical transactions of the Royal Society of London Series B, Biological sciences. 2010; 365: 1653-62. doi:10.1098/rstb.2009.0254.

7. Liu D, Matzuk MM, Sung WK, Guo O, Wang P, Wolgemuth DJ. Cyclin A1 is required for meiosis in the male mouse. Nature genetics. 1998; 20: 377-80. doi:10.1038/3855.
8. Lele KM, Wolgemuth DJ. Distinct regions of the mouse cyclin A1 gene, Ccna1, confer male germ-cell specific expression and enhancer function. Biol Reprod. 2004; 71: 1340-7. doi:10.1095/biolreprod.104.030387.

9. Panigrahi SK, Vasileva A, Wolgemuth DJ. Sp1 transcription factor and GATA1 cis-acting elements modulate testis-specific expression of mouse cyclin A1. PloS one. 2012; 7: e47862. doi:10.1371/journal.pone.0047862.

10. Ravnik SE, Wolgemuth DJ. Regulation of meiosis during mammalian spermatogenesis: the A-type cyclins and their associated cyclin-dependent kinases are differentially expressed in the germ-cell lineage. Developmental biology. 1999; 207: 408-18. doi:10.1006/dbio.1998.9156.

11. Yang R, Morosetti R, Koeffler HP. Characterization of a Second Human Cyclin A That Is Highly Expressed in Testis and in Several Leukemic Cell Lines. Cancer Research. 1997; 57: 913-20.

12. Persson JL, Zhang Q, Wang XY, Ravnik SE, Muhlrad S, Wolgemuth DJ. Distinct roles for the mammalian A-type cyclins during oogenesis. Reproduction. 2005; 130: 411-22. doi:10.1530/rep.1.00719.

13. Krug U, Yasmeen A, Beger C, Baumer N, Dugas M, Berdel WE, et al. Cyclin A1 regulates WT1 expression in acute myeloid leukemia cells. International journal of oncology. 2009; 34: 129-36.

14. Fuchimoto D-i, Mizukoshi A, Schultz RM, Sakai S, Aoki F. Posttranscriptional Regulation of Cyclin A1 and Cyclin A2 During Mouse Oocyte Meiotic Maturation and Preimplantation Development. Biology of Reproduction. 2001; 65: 986-93. doi:10.1095/biolreprod65.4.986.

15. Joshi AR, Jobanputra V, Lele KM, Wolgemuth DJ. Distinct properties of cyclin-dependent kinase complexes containing cyclin A1 and cyclin A2. Biochemical and biophysical research communications. 2009; 378: 595-9. doi:10.1016/j.bbrc.2008.11.077.

16. Muller-Tidow C, Ji P, Diederichs S, Potratz J, Baumer N, Kohler G, et al. The cyclin A1-CDK2 complex regulates DNA double-strand break repair. Molecular and cellular biology. 2004; 24: 8917-28. doi:10.1128/MCB.24.20.8917-8928.2004.

17. Kalaszczynska I, Geng Y, lino T, Mizuno S, Choi Y, Kondratiuk I, et al. Cyclin $\mathrm{A}$ is redundant in fibroblasts but essential in hematopoietic and embryonic stem cells. Cell. 2009; 138: 352-65. doi:10.1016/j.cell.2009.04.062.

18. Johnson J, Canning J, Kaneko T, Pru JK, Tilly JL. Germline stem cells and follicular renewal in the postnatal mammalian ovary. Nature. 2004; 428: 145-50. doi:10.1038/nature02316.

19. White YA, Woods DC, Takai Y, Ishihara O, Seki H, Tilly JL. Oocyte formation by mitotically active germ cells purified from ovaries of reproductive-age women. Nature medicine. 2012; 18: 413-21. doi:10.1038/nm.2669. 